\title{
Prediction of Fat Mass and Validation Using 3D-Whole Body Scanner in Healthy Indian Males
}

\author{
L. Robert VARTE, Shweta RAWAT, Inderjeet SINGH, Shilpa CHOUDHARY, Suchitra SINGH, \\ Deepika KAKKAR, Yashmita CHAUDHARY, Usha PANJWANI, Bhuvnesh KUMAR \\ Defence Institute of Physiology and Allied Sciences (DIPAS), \\ Defence Research and Development Organisation (DRDO), Delhi, India
}

DOI: $10.15221 / 18.195$ http://dx.doi.org/10.15221/18.195

\begin{abstract}
Background: BMI generally overestimates adiposity (i.e. body fat tissue) and underestimates excess body fat on those with less lean body mass.

Aim: We wanted to assess the hypothesis that Fat Mass (FM) measured by bio impedance analysis (BIA) is comparable to the predicted Body Fat Mass (BFM) using 3D scanned anthropometric dimensions.

Methods: The present paper investigates whether anthropometric measurements using 3D whole body scanner can provide clinically reliable prediction equation to assess adiposity. 3D whole body scanner provides a fast and precise alternative where the scanner gives upto 140 measurements within a few seconds. Intra-and inter-individual error margins in traditional anthropometric measurements frequently arises for large sample studies, besides, manually taking measurements are time-consuming and challenging to perform within acceptable limits. Six hundred and eight (608) healthy adults were scanned using a 3D whole body scanner and their body composition was measured using the Tanita Bipodal bioelectrical impedance analysis (BIA). 486 formed the development group (for the prediction equation) and $20 \%$ of the total (i.e. 122 formed the validation group) based on alphabetical order of participant's name. Linear regressions were performed to predict an equation wherein the body circumferential measurements like Waist Girth, Hip Girth and Chest Girth were predictors and Fat Mass was the dependent variable.
\end{abstract}

Results: Predictive body composition equation based on volumetric body circumference (girth) proposed for healthy Indian males is FM $=0.420$ (Waist Girth) + 0.241 (Chest Girth) + 0.051 (Hip Girth) - 51.817. The predicted fat mass value was used for the validated population and we did not see much of a difference between the predicted and measured fat mass. The mean age among the 608 volunteers was $32.54 \pm 6.3$ years, weight was $71.26 \mathrm{~kg} \pm 7.8 \mathrm{~kg}$ and BMI was $24.1 \pm 2.57 \mathrm{~kg} / \mathrm{mt}^{2}$. Average difference between body fat measured by BIA - predicted body fat mass was $0.13 \mathrm{~kg}$, median $0.50 \mathrm{~kg}$, IQR: 0.80 to $0.20 \mathrm{~kg}$, adjusted $R^{2} 0.74$.

Conclusions: 3D whole body scanner technology offer defined and accurate automated anthropometric dimensions and measurements of body shape. Further studies are warranted to reveal important relationships between body shape, body composition and metabolic health across sex, age, BMI and ethnicity groups.

Keywords: body fat mass, circumference, Indian males, prediction, validation

\section{Introduction}

The commonly used BMI for adiposity risks have lately been less popular, with many index preferred over BMI to predict better predict adiposity related CVD. Other indexes preferred to assess adiposity include Waist Circumference, Waist Hip Ratio, Waist Stature Ratio, Body Adiposity Index, etc. A recent method where body circumferences are obtained using a whole body human scanner is the latest technique. In this, a 3D whole body volume scanner gives the circumference of an individual scan without clothes. Because BMl generally overestimates adiposity (i.e. body fat tissue) and underestimates excess body fat on those with less lean body mass, the importance of adiposity studies both in the civilian and defence sectors have and will continue to gain importance as modern lifestyle related changes in diet and exercise regimen continues to undergo changes with time.

Prior few years ago, circumferences or girths of human body were measured using measuring tapes. With the advent of 3D whole body scanner, the body circumferences can be measured closer and much better sans human contact, thus doing away with awkward measuring situations both for the volunteer as well as the examiner. 
The use of BMI is and will always be important in population health studies, however BMI alone is not considered rigorous enough by many researchers for assessing adiposity as it is possible that an individual with greater muscle mass, such as athletes may be large in term of total body weight, but not obese. In the military population, the specificity of BMI needs to be addressed much more carefully because muscle mass maybe a greater component of BMI in the military than in the general population owing to heighten exercise regimens and activity levels (Sundin et al. 2011).

Abdominal obesity is a major contributor of CVDs like hypertension, diabetes mellitus and hypercholesterolemia (Norafidah et al. 2013). Thus, it is with utmost care that obesity assessment studies are undertaken so that individuals who are more prone to have high abdominal circumference adiposity even though they have normal BMI are not neglected. Body weight is influenced by more than fat tissue, including high muscle mass, and the relationship between BMI and health can vary with ethnicity.

In the US Armed Forces, obesity is estimated to be 13\% (Bray et al. 2008). In India, among the general population, it is reported that $18.9 \%$ of Indian men are either overweight or obese (NFHS 2015-16). The Indian Armed Forces comprising of individuals from all over the country are not unaffected by the obesity epidemic sweeping across the states. There are some literatures that report the prevalence of overweight or obesity among some defence sectors either by BMI or body fat percent. It ranges from $20.66 \%$ by BMl among 121 healthy male volunteers from a Naval hospital's staff study to $47.11 \%$ by body fat among the same population (Singh SP et al. 2008). Among healthy Gorkha soldiers $(n=388)$, it was found that $13.1 \%$ of them were found to be overweight based on their high body fat content (Varte et al. 2013).

An essential requirement in the Armed Forces is for the forces to be on their toes and high physical fitness is given top priority, so it is important to accurately determine their body composition. Body mass index (BMI) has been extensively used to define overall obesity. But, BMI does not differentiate on body fat distribution (Fernández et al. 2003; Wang et al. 1994). High BMl values may not necessarily be because of increase in fat mass, but rather it can be an increase of fat free mass (Friedl, 2004, Heinrich et al. 2008). Excess adipose tissue or high body fat percentage is related to increased morbidity and mortality risks (Mokdad et al. 2001) and this being true irrespective of whether one is a serving personnel or civilian population, the importance of studying body fat is all the more important.

\section{Materials and Methods}

The present study investigated whether anthropometric circumferential measurements using 3D whole body scanner can provide clinically reliable prediction equation to assess adiposity.

3D scanner was used for whole human body scanned on 608 Indian male soldiers who were volunteers for the study with a mean age of 32.54 years \pm 6.32 years, aged $20-49$ years wearing light apparel. All the volunteers stood inside the 3D scanner booth without shoes while being scanned. Body weight of the subjects wearing minimal clothing and barefoot to the nearest $0.1 \mathrm{~kg}$, were measured using the Tanita weighing machine (Tanita Corporation, Tokyo, Japan). The 3D while body scanner results digital image/avatar of the individual scanned and the distribution of body mass distribution and the deposition of fat mass can be visualised and processed better as compared to manual measurements.

The 3D scanner gives circumferential measurements of the human body and we wanted to see if these body circumferences from the body scans could serve as potential predictors for body fat percentage. Each body scan resulted in over 140 measurements of the human body shape and size that can be analysed for their correlation with body fat mass. The 3D anthropometric data requires digital post-processing, and then only were the data on body volume and areas of fat deposition could be used to calculate an estimate of body fat percentage.

\section{Statistical Analysis}

We used the 2-compartment method in estimating body fat. In general, body composition is divided into two major components, namely, fat mass (FM) and fat free mass (FFM). FM includes essential and energy stores or storage fat while FFM includes water, muscles, bones, minerals, proteins and other tissues of the body. About one-third of energy stores in adults are deposited subcutaneously or externally. The variance inflation factors (VIF) was also calculated to assess multi-collinearity (VIF $>10)$, and used residual analysis to verify assumptions of linear regression analysis as well as 
differences between FM determined by bio-electrical impedance analysis (BIA) and those estimated by body circumferences. Models for predicting body fat mass were developed using multiple regression analysis with chest circumference, waist circumference and hip circumference evaluated as potential independent variables. Correlation relation was used in model development and derivation of prediction equation models by using forward stepwise regression. Variables where $r$ $>0.5$, were selected to form the equation. Normal distribution of data was verified using kurtosis and skewness test. The predicted equation with an adjusted $R^{2}$ of 0.74 was evaluated for the validated population. All statistical analyses were carried out using Statistical Product and Service Solution (SPSS (version 21, SPSS Inc, Chicago).

In this study, we aimed to develop a method that wherein instead of $\mathrm{BMI}$, some alternate anthropometric measurements that show good statistical correlation that focuses on volumetric measurements rather than weight will be used to devise a prediction equation for fat mass.

Age: Age was calculated as the difference between the date of study and the date of birth of the person investigated.

\section{Body Composition}

Individuals who were to be scanned were requested the night before the scan day to report to the scanning facility early morning, and then their weight were measured without clothes, shoes and socks to the nearest $0.1 \mathrm{~kg}$ using the Tanita TBF-310 Body Composition Analyzer (Tanita Corporation, Tokyo, Japan). In conducting a study of 608 personnel belonging to different unit locations, BIA was found to be more feasible in a study involving military personnel for its ease of operation and reliability for field conditions (Prentice et al. 2001). Tanita analysers have also compared favourably with DEXA ( $r=0.94 \mathrm{p}<0.001$ ) (Nunez et al. 1997; Jebb et al. 2000).

Fat mass (FM) (kg): Actual fat mass (in kilograms) in the body.

Fat free mass (FFM) (kg): Fat Free Mass is comprised of muscle, bone, tissue, water and all other fat free mass in the body. A healthy ratio for Fat Free Mass to Fat Mass is approximately $5: 1$ for female and $7: 1$ for male.

\section{Results}

Descriptive statistics of the study population in Table 1 shows eight anthropometric parameters with mean and standard error and range of 608 personnel of the Indian Armed Forces divided into two sets. The first set consist of 486 individuals which form the development group and $20 \%$ of 608 i.e. 122 number of volunteers form the validation group. The population was arranged based on their name in alphabetical order. The p-value of the two groups was seen for all eight variables and no statistical significant differences were found among them. There is a need to achieve a better anthropometric diagnosis in health, especially with regard to BMI and body fat, especially among the Armed Forces to refine diagnosis using body composition. In this study, fat mass (FM) prediction equations for the Armed Forces were developed by using body circumferences achieved by 3D whole body scanner using white light. The prediction equation is easily reproducible, as indicated by the high intra-class correlation coefficient, an important aspect, as errors related to measurement techniques may amplify variance in data, making correlation, regression and variance statistical methods not viable. Quality control involving measurement error is a pre-requisite to increase accuracy and better interpretation of results (Goto and Mascie -Taylor, 2007).

Predictive body composition equation based on volumetric body circumference (girth) proposed for healthy Indian males is FM = 0.420 (Waist Girth) + 0.241 (Chest Girth) + 0.051 (Hip Girth) - 51.817.

The predicted fat mass value was used for the validated population and we did not see much of a difference between the predicted and measured fat mass. The mean age among the 608 volunteers was $32.54 \pm 6.3$ years, weight was $71.26 \mathrm{~kg} \pm 7.8 \mathrm{~kg}$, and BMl was $24.1 \pm 2.57 \mathrm{~kg} / \mathrm{mt}^{2}$. Average difference between body fat measured by BIA - predicted body fat mass was $0.13 \mathrm{~kg}$, median $0.50 \mathrm{~kg}$, IQR: 0.80 to $0.20 \mathrm{~kg}$, adjusted $\mathrm{R}^{2} 0.74$.

\section{Discussion}

The importance of adiposity studies both in the civilian and defence sectors have and will continue to gain importance as modern lifestyle related changes in diet and exercise regimen continues to undergo changes with time. However, the commonly used BMI for assessing adiposity risks have 
lately been less popular, with many index preferred over BMI to predict better predict adiposity related CVD, because BMI generally overestimates adiposity (i.e. body fat tissue) and underestimates excess body fat on those with less lean body mass. Body circumference measurements and various indexes like Waist Hip ratio, Waist Stature ratio and Waist Circumference cut offs have been suggested that can assess adiposity besides BMI.

In this study, we wanted to assess the hypothesis that Fat Mass (FM) measured by bio impedance analysis (BIA) is comparable to the predicted Body Fat Mass (BFM) using 3D scanned anthropometric circumference measurements. With the advent of 3D whole body scanner, body circumferences can be measured closer and much better sans human contact, thus doing away with awkward measuring situations both for the volunteer as well as the examiner. Many studies have reported that both visceral fat increase and an expanded girth (Wajchenberg et al. 2002, Nguyen-Duy et al. 2003) have been associated with increase in insulin resistance, diabetes, risk for coronary heart disease and hypertension (Kissebah et al. 1989, Kissebah et al. 1982, Despres et al. 1990, Pouliot et al. 1994, Pouliot et al. 1990, Lemieux et al. 1996, Wildman et al. 2008).

BMI has some limitations when used as an indicator of percent of body fat mass and may be misleading in this regard, particularly in men (Nuttall, FQ 2015). Is it BMI alone, total fat mass, or the distribution of body fat, i.e., visceral versus subcutaneous, or upper body fat accumulation (as determined by abdominal circumference), or a waist/hip ratio, or some combination of these, that can best assess adiposity? The EPIC study reported that the location of fat accumulation is much more important than merely BMI (Pischon et al. 2008).

For the first time among Indian defence personnel, a 3D whole body scanner was used to estimate adiposity by body fat value using anthropometric scanned body circumferences. The prediction equation developed in this study showed that body circumferential measurements obtained using $3 \mathrm{D}$ whole body scanner can accurately estimate body fat. Earlier, a very important limitation of BMI for diagnosing obesity in an individual is the slight inaccuracy in those with intermediate BMI values and among athletes and fit individuals who may have high body weight but less fat exhibiting high BMI. We wanted to see whether BIA measured Fat Mass is comparable to the predicted Body Fat Mass predicted using 3D scanned anthropometric dimensions.

Among the armed force, a visit to a clinic may be dreaded for many reasons, so this method of assessing their fat content without contact has potential clinical role in the armed forces, for it saves a soldier's time and it is easy to estimate. Besides, this method can be an important element in those individuals who want to avoid unnecessary anxiety or being in weight loss programs. (Medina-Inojosa $J$ et al. 2017).

Strength: This study is important for its sample size $(n=608)$ who were personnel who belonged to different ethnicity and comprised of a broad spectrum of age from 20-49 years. The anthropometric body measurements on personnel were taken on nude body and more accurate than manual measurements, as thickness of clothes was not included in the scan. Besides, experimenter error became minimal in light of the fact that no physical contact was made for measuring the individuals.

The 3D scanner used in this study is non-invasive and technically not that difficult to operate, though it is not portable scanner to be used in field conditions, the present study did take the scanner to various field units, dismantling and setting it up in different units, hence the importance of this study cannot be ignored.

Limitations: Though prediction equation for fat mass was given for the combined age groups, the age group range was quite large, from 20-49 years. Fat content varies for different age groups, which this study did not segregate and looked into further.

\section{Conclusion}

To conclude, 3D whole body scanner can be used to estimate body fat mass from the body circumference measurements using the prediction equation developed for easy and effective body composition evaluation.

Acknowledgement: Authors would like to extend special thanks to the SD Branch and to the personnel of different units for their time and are grateful to all the officers and PBOR whose help they received in the field.

Conflict of interest: There are no competing interests of any type in relation to the study. 
Table 1: Comparative Description between Development Set Vs. Validation Set And T Test

\begin{tabular}{|c|c|c|c|c|c|c|c|c|c|}
\hline \multirow[b]{3}{*}{ Age } & \multicolumn{4}{|c|}{ Development group, $n=486$} & \multicolumn{4}{|c|}{ Validation group, $n=122$} & \multirow{3}{*}{$\begin{array}{c}\begin{array}{c}\mathbf{p}- \\
\text { value }\end{array} \\
0.33\end{array}$} \\
\hline & \multirow{2}{*}{$\begin{array}{l}\text { Mean } \\
32.54\end{array}$} & \multirow{2}{*}{$\begin{array}{l}\begin{array}{l}\text { SE of } \\
\text { Mean }\end{array} \\
0.26\end{array}$} & \multicolumn{2}{|l|}{ RANGE } & \multirow{2}{*}{$\begin{array}{l}\text { Mean } \\
33.09\end{array}$} & \multirow{2}{*}{$\begin{array}{l}\begin{array}{l}\text { SE of } \\
\text { Mean }\end{array} \\
0.53\end{array}$} & \multicolumn{2}{|l|}{ Range } & \\
\hline & & & 20.00 & 49.00 & & & 20.00 & 49.00 & \\
\hline Stature & 171.88 & 0.20 & 145.00 & 189.60 & 171.95 & 0.45 & 159.00 & 185.00 & 0.44 \\
\hline Weight & 71.26 & 0.32 & 53.20 & 108.00 & 71.07 & 0.70 & 54.40 & 92.00 & 0.80 \\
\hline Fat mass & 14.23 & 0.20 & 4.00 & 40.80 & 14.10 & 0.41 & 4.40 & 28.40 & 0.23 \\
\hline BMI & 24.12 & 0.10 & 16.00 & 37.00 & 24.07 & 0.22 & 16.00 & 31.50 & 0.51 \\
\hline Hips girth & 98.21 & 0.29 & 72.00 & 118.70 & 98.13 & 0.59 & 72.20 & 116.50 & 0.11 \\
\hline Waist girth & 86.77 & 0.30 & 67.90 & 113.90 & 86.91 & 0.67 & 67.90 & 103.90 & 0.62 \\
\hline Chest girth & 102.27 & 0.22 & 86.50 & 122.40 & 102.70 & 0.47 & 89.00 & 116.60 & 0.79 \\
\hline
\end{tabular}

Independent 't' test

Figure 1: The correlation between FM measured by BIA and predicted FM was $R 2=0.74$
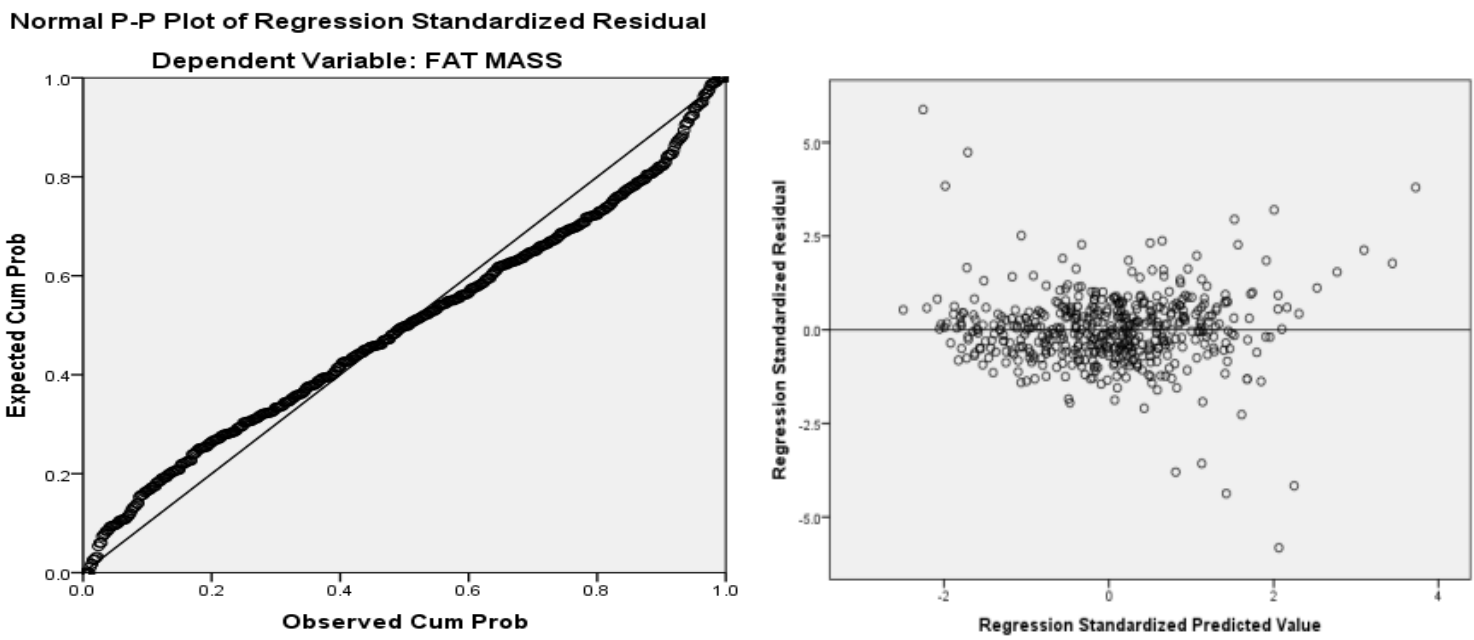

Figure 1 shows the normal plot of standardized residual for dependent variable FM measured by BIA and the FM predicted by the new prediction equation.

\section{References}

Bray, R.M., Hourani, L.L., Olmsted, K.L. et al. (2008). Department of Defense survey of health related behaviors among active duty military personnel. Report prepared for TRICARE Management Activity, Office of the Assistant Secretary of Defense (Health Affairs) and U.S. Coast Guard. Retrieved from http://www.fedprac.com/PDF/028050001s.pdf. Accessed 24 June 2013.

Fernández, J.R., Heo, M., Heymsfield, S.B. et al. (2003). Is percentage body fat differentially related to body mass index in Hispanic Americans, African Americans, and European Americans? The American Journal of Clinical Nutrition. 77(1): 71-75.

Despres, J.P., Moorjani, S., Lupien, P.J., Tremblay, A, Nadeau. A., Bouchard, C. (1990) Regional distribution of body fat, plasma lipoproteins, and cardiovascular disease. Arteriosclerosis. 10 (4): 497511.

Friedl, K.E. (2004). Can you be large and not be obese? The distinction between body weight, body fat, and abdominal fat in occupational standards. Diabetes Technol Ther. 6, 732-749. 
Goto, R., Heinrich, K.M., Jitnarim, N., Suminsk,i R.R. et al. (2008). Obesity classification in military personnel: a comparison of body fat, waist circumference and body mass index measurements. Mil Med. 173, 67-73.

Jebb, S.A., Cole, T.J., Doman, D., Murgatroyd, P.R., Prentice, A.M. (2000). Evaluation o the novel Tanitaq body-fat analyser to measure body composition by comparison with a four-compartment model. Br J Nutr. 83: 115-122.

Kissebah, A.H., Freedman, D.S., Peiris, A.N. (1989). Health risks of obesity. Med Clin North Am. 73 (1): 111-138.

Kissebah, A.H., Vydelingum, N., Murray, R., et al. (1982). Relation of body fat distribution to metabolic complications of obesity. J Clin Endocrinol Metab. 4 (2): 254-260.

Lemieux, S., Prud'homme, D., Tremblay, A., Bouchard, C., Despres, J.P. (1996). Anthropometric correlates to changes in visceral adipose tissue over 7 years in women. Int $\mathrm{J}$ Obes Relat Metab Disord. 20 (7): 618-624.

Medina-Inojosa, J., Somers, V., Jenkins, S., Zundel, J., Johnson, L., et al. (2017). Validation of a White-light 3D Body Volume Scanner to Assess Body Composition. Obes Open Access 3(1):doi http://dx.doi.org/10.16966/2380-5528.127

Mokdad, A.H., Ford, E.S., Bowman, B.A. et al. (2001). Prevalence of obesity, diabetes, and obesityrelated health risk factors. JAMA. 289 (1), 76-79.

National Family Health Survey (NFHS-4). 2015-16. National Fact Sheet. INDIA (Provisional data). International Institute for Population Sciences, Mumbai. Ministry of Health and Family Welfare. Government of India.

Norafidah, A.R., Azmawati, M.N., and Norfazilah, A. (2013). Factors influencing abdominal obesity by waist circumference among normal BMI population. Malaysian Journal of Public Health. 13(1):37-47.

Nguyen-Duy, T.B., Nichaman, M.Z., Church, T.S., Blair, S.N., Ross, R. (2003).Visceral fat and liver fat are independent predictors of metabolic risk factors in men. Am J Physiol Endocrinol Metab. 284 (6): E1065-E1071.

Nunez, C., Gallagher, D., Visser, M., Pi-Sunyer, F.X., Wang, Z., Heymsfield, S.B. (1997).

Bioimpedance analysis: evaluation of leg-to-leg system bases on pressure contact foot-pad electrodes. Med Sci Sports Exerc. 29(4):524-531.

Nuttall, Frank Q. (2015). Body Mass Index: Obesity, BMI, and Health A Critical Review. Nutrition Today: May/June 2015 - Volume 50 - Issue 3 - p 117-128.

Pischon, T., Boeing, H., Hoffmann, K., et al. (2008).General and abdominal adiposity and risk of death in Europe. N Engl J Med. 359 (20): 2105-2120.

Pouliot, M.C., Despres, J.P., Lemieux, S., et al. (1994). Waist circumference and abdominal sagittal diameter: best simple anthropometric indexes of abdominal visceral adipose tissue accumulation and related cardiovascular risk in men and women. Am J Cardiol. 73 (7): 460-468.

Pouliot, M.C., Despres, J.P., Nadeau, A., et al. (1990). Associations between regional body fat distribution, fasting plasma free fatty acid levels and glucose tolerance in premenopausal women. Int J Obes. 14 (4): 293-302.

Prentice, A.M., Jebb, S.A. (2001). Beyond body mass index. Obes Rev. 2(3):141-147.

Singh, S.P., Sikri, G. and Garg, M.K. (2008). Body mass index and obesity: Tailoring "cut-off" for an Asian Indian male population. MJAFI. 64, 350-353.

Sundin, J., Fear, N.T., Wessely, S. and Rona, R.J. (2011). Obesity in the UK armed forces: Risk factors. Military Medicine. 176(5), 507-512.

Varte, L.R., Rawat, S., and Singh, I. (2013). Relationship of Body Mass Index, Waist Circumference and Waist-Stature Ratio with Body Fat of the Indian Gorkha Population. Mal J Nutr 19(2): 185 - 192. Wajchenberg, B.L., Giannella-Neto, D., da Silva, M.E., Santos, R.F. (2002). Depot-specific hormonal characteristics of subcutaneous and visceral adipose tissue and their relation to the metabolic syndrome. Horm Metab Res. 34 (11-12): 616-621.

Wang, J., Thorton, J.C., Russel, M., Burastero, S., Heymsfield, S. and Pierson, Jr .R.N. (1994). Asians have lower body mass index (BMI) but higher percent body fat than do whites: comparisons of anthropometric measurements. The American Journal of Clinical Nutrition. 60(1):23-28.

Wildman, R.P., Muntner, P., Reynolds, K., et al. (2008). The obese without cardiometabolic risk factor clustering and the normal weight with cardiometabolic risk factor clustering: prevalence and correlates of 2 phenotypes among the US population (NHANES 1999-2004). Arch Intern Med. 168 (15): 16171624. 